\title{
A Severe Form of Churg-Strauss Syndrome Complicated with Acute Cardiac Failure and Rapidly Progressive Peripheral Neuropathy - A Possible Effect of Intravenous Immunoglobulin Therapy
}

\author{
Daisuke Kobayashi ${ }^{1}$, Yoko Wada ${ }^{1}$, Takuma Takata ${ }^{2}$, Toshiyuki Koya ${ }^{3}$, Shuichi Murakami ${ }^{1}$, \\ Takuya Ozawa ${ }^{4}$, Yoshifusa Aizawa ${ }^{4}$, Takeshi Kuroda ${ }^{5}$, Masaaki Nakano ${ }^{6}$ and Ichiei Narita ${ }^{1}$
}

\begin{abstract}
We report a case of Churg-Strauss syndrome (CSS) complicated by severe cardiac failure and peripheral neuropathy. Two courses of methylprednisolone pulse therapy were unable to control the disease activity. Repeated intravenous administration of high-dose human immunoglobulin (IVIg) was added together with intravenous cyclophosphamide pulse therapy (IVCY), and the patient's cardiac function and neurological symptoms were gradually ameliorated without any adverse event. Although glucocorticoid and cyclophosphamide comprise the standard therapy for patients with CSS, a number of patients with severe complications appear to be resistant to such conventional treatment. IVIg is thought to be an effective therapeutic option for such patients.
\end{abstract}

Key words: Churg-Strauss syndrome (CSS), intravenous administration of a high-dose human immunoglobulin (IVIg), acute cardiac failure, peripheral neuropathy

(Intern Med 50: 925-929, 2011)

(DOI: 10.2169/internalmedicine.50.4648)

\section{Introduction}

Churg-Strauss syndrome (CSS) is a necrotizing smallvessel vasculitis with extravascular granulomas and eosinophilic infiltrates, which preferentially affects the capillaries, arterioles, and venules (1-3). Although corticosteroids and cyclophosphamide are highly effective for the treatment of CSS, some patients with severe CSS often show resistance to conventional treatment. Recently, several case reports and small case studies have indicated the possible effect of intravenous administration of high-dose human immunoglobulin (IVIg) for CSS patients who are refractory to such standard therapies (4-8).

Here we report a severe case of CSS associated with rap- idly progressive cardiac failure and peripheral neuropathy, which was treated successfully with a combination of corticosteroid, intravenous cyclophosphamide pulse therapy (IVCY), and IVIg.

\section{Case Report}

A 51-year-old woman diagnosed as having CSS was transferred to our hospital because of rapidly progressive heart failure and peripheral neuropathy. Initially she was admitted to another hospital because of an acute exacerbation of asthmatic symptoms, lower-limb paresthesia, and fever. On physical examination, she had no skin eruption. Chest auscultation revealed wheeze sound at the bilateral chest, and no abnormalities were found in the abdomen. Neuro-

${ }^{1}$ Division of Clinical Nephrology and Rheumatology, Department of Medicine II, Niigata University Graduate School of Medical and Dental Sciences, Japan, ${ }^{2}$ Department of Internal Medicine, Nagaoka Central General Hospital, Japan, ${ }^{3}$ Division of Respiratory Medicine, Department of Medicine II, Niigata University Graduate School of Medical and Dental Sciences, Japan, ${ }^{4}$ Division of Cardiology, Department of Medicine I, Niigata University Graduate School of Medical and Dental Sciences, Japan, ${ }^{5}$ Health Administration center of Niigata University, Japan and ${ }^{6}$ Department of Medical Technology, School of Health Sciences, Faculty of Medicine, Niigata University, Japan

Received for publication October 7, 2010; Accepted for publication December 6, 2010

Correspondence to Dr. Daisuke Kobayashi, joifa602@hotmail.com 
Table 1. Laboratory Data on Admission to Our Hospital

\begin{tabular}{|c|c|c|c|c|c|}
\hline \multicolumn{3}{|l|}{ Blood count } & \multicolumn{3}{|c|}{ Serum chemistry } \\
\hline WBC & 12250 & $/ \mu \mathrm{L}$ & AST & 25 & IU/L \\
\hline Eos & 0.9 & $\%$ & $\mathrm{ALT}$ & 11 & IU/L \\
\hline $\mathrm{RBC}$ & $412 \times 1$ & $/ \mu \mathrm{L}$ & $\mathrm{LDH}$ & 479 & IU/L \\
\hline $\mathrm{Hb}$ & 10.4 & $\mathrm{~g} / \mathrm{dL}$ & YGTP & 30 & $\mathrm{IU} / \mathrm{L}$ \\
\hline $\mathrm{Ht}$ & 35.4 & $\%$ & ALP & 196 & $\mathrm{U} / \mathrm{L}$ \\
\hline \multirow[t]{2}{*}{ Plt } & \multirow{2}{*}{\multicolumn{2}{|c|}{$17.5 \times 10^{4} / \mu \mathrm{L}$}} & TB & 0.6 & $\mathrm{mg} / \mathrm{dL}$ \\
\hline & & & ChE & 136 & IU/L \\
\hline \multicolumn{3}{|c|}{ Coagulation tests } & UN & 30 & $\mathrm{mg} / \mathrm{dL}$ \\
\hline APTT & \multicolumn{2}{|c|}{$28.4 \mathrm{sec}$ (control 26.2) } & $\mathrm{Cr}$ & 0.7 & $\mathrm{mg} / \mathrm{dL}$ \\
\hline Fbg & 514 & $\mathrm{mg} / \mathrm{dL}$ & UA & 7.2 & $\mathrm{mg} / \mathrm{dL}$ \\
\hline FDP & 9.5 & $\mu \mathrm{g} / \mathrm{mL}$ & $\mathrm{Na}$ & 138 & $\mathrm{mEq} / \mathrm{L}$ \\
\hline D-dimer & 4.8 & $\mathrm{mg} / \mathrm{dL}$ & $\mathrm{K}$ & 3.6 & $\mathrm{mEq} / \mathrm{L}$ \\
\hline ATIII & 127 & $\%$ & $\mathrm{Cl}$ & 98 & $\mathrm{mEq} / \mathrm{L}$ \\
\hline \multicolumn{3}{|c|}{ Immunological Findings } & \multicolumn{3}{|c|}{ Blood Gas Analysis(10L/min reserver mask) } \\
\hline CRP & 13.69 & $\mathrm{mg} / \mathrm{dL}$ & $\mathrm{pH}$ & 7.51 & \\
\hline IgG & 731 & $\mathrm{mg} / \mathrm{dL}$ & $\mathrm{PaCO} 2$ & 35.1 & Torr \\
\hline $\operatorname{IgM}$ & 83 & $\mathrm{mg} / \mathrm{dL}$ & $\mathrm{PaO} 2$ & 58.3 & Torr \\
\hline $\operatorname{IgA}$ & 168 & $\mathrm{mg} / \mathrm{dL}$ & $\mathrm{HCO}^{-}$ & 28.5 & $\mathrm{~mol} / \mathrm{L}$ \\
\hline C3 & 131.9 & $\mathrm{mg} / \mathrm{dL}$ & & & \\
\hline $\mathrm{C} 4$ & 40.5 & $\mathrm{mg} / \mathrm{dL}$ & Urynalysis & & \\
\hline CH50 & 51 & $\mathrm{U} / \mathrm{mL}$ & Protein & 0.3 & g/day \\
\hline ANA & $<20$ & index & Sugar & 0.8 & g/day \\
\hline MPO-ANCA & $<10$ & $\mathrm{IU} / \mathrm{mL}$ & $24 \mathrm{hrCcr}$ & 72.5 & $\mathrm{~mL} / \mathrm{min}$ \\
\hline PR3-ANCA & $<3.5$ & $\mathrm{EU}$ & Sediment & & \\
\hline \multirow[t]{2}{*}{$\mathrm{RF}$} & 30.8 & $\mathrm{IU} / \mathrm{mL}$ & $\mathrm{RBC}$ & $5-9$ & $/ \mathrm{hpf}$ \\
\hline & & & WBC & $20-29$ & $/ \mathrm{hpf}$ \\
\hline \multicolumn{6}{|c|}{ Other Findings } \\
\hline \multicolumn{2}{|c|}{ CMV antigenemia $2 / 4$} & $(+)$ & & & \\
\hline $\mathrm{BNP}$ & 980.2 & $\mathrm{pg} / \mathrm{dL}$ & & & \\
\hline
\end{tabular}

Table 2. Echocardiographic Findings

\begin{tabular}{lccc}
\hline & July 2009 & Sep. & After 3 courses of IVIG \\
\hline IVST (mm) & 8.9 & 13 & 11 \\
PWT (mm) & 9.6 & 22 & 18 \\
TR/PG (mmHg) & trivial & 70 & trivial \\
SV (mL) & 70.7 & 19.2 & 66 \\
PG within LV (mmHg) & trivial & 81 & trivial \\
\hline
\end{tabular}

IVST; interventricular septum thickness, PWT; posterior left ventricular wall thickness, TR; tricuspid regurgitation, PG; pressure gradient, SV; stroke volume, LV; left ventricle

logical examinations showed mononeuritis multiplex. Chest radiography showed pulmonary opacities. Laboratory studies showed the following values: white blood cell count, $18,210 / \mathrm{mm}^{3}$ with $57.8 \%$ eosinophils (eosinophil count, $10,525 / \mathrm{mm}^{3}$ ); C-reactive protein, $11.29 \mathrm{mg} / \mathrm{dL}$; antinuclear antibody, myeloperoxidase-specific antineutrophil cytoplasmic antibody (MPO-ANCA), and proteinase-3 specific antineutrophil cytoplasmic antibody (PR3-ANCA), negative. With a history of bronchial asthma, pulmonary infiltration, eosinophilia, and mononeuritis multiplex, she fulfilled the American College of Rheumatology (1990) criteria for Churg-Strauss syndrome (CSS). Despite administration of one course of pulse methylprednisolone (mPSL) followed by oral administration of prednisolone (PSL) $40 \mathrm{mg}$ daily, the numbness of the extremities and hypoxemia rapidly progressed, and she was transferred to the emergency ward in our hospital.

When transferred, her blood pressure was $76 / 55 \mathrm{mmHg}$, and arterial blood gas analysis showed a significant decrease of $\mathrm{PaO}_{2}$ to 58.1 Torr during administration of oxygen at 10 L/min. Other laboratory findings are shown in Table 1. Chest radiography demonstrated pleural effusion and pulmonary edema. Although echocardiography 3 weeks earlier had shown normal cardiac function with a normal left ventricular (LV) wall thickness, a repeat echocardiogram at our hospital revealed that severe wall thickening of the LV had decreased the left ventricular cavity and stroke volume (Table 2). A hemodynamic study using a Swan-Ganz catheter showed a low cardiac index $\left(1.8 \mathrm{~L} / \mathrm{min} / \mathrm{m}^{2}\right)$, high pulmonary capillary wedge pressure $(35 \mathrm{mmHg}$ ), and high pulmonary artery pressure $(70 / 50 \mathrm{mmHg})$. Severe hypoxemia and cardiac dysfunction also caused anuric acute renal failure.

The patient was intubated for mechanical ventilation and treated with continuous hemodiafiltration. Endomyocardial biopsy could not be performed because of her severe disease state, but the clinical course suggested that cardiac failure was due to CSS endomyocarditis. A second mPSL pulse was administered, and the patient was extubated on day 13 

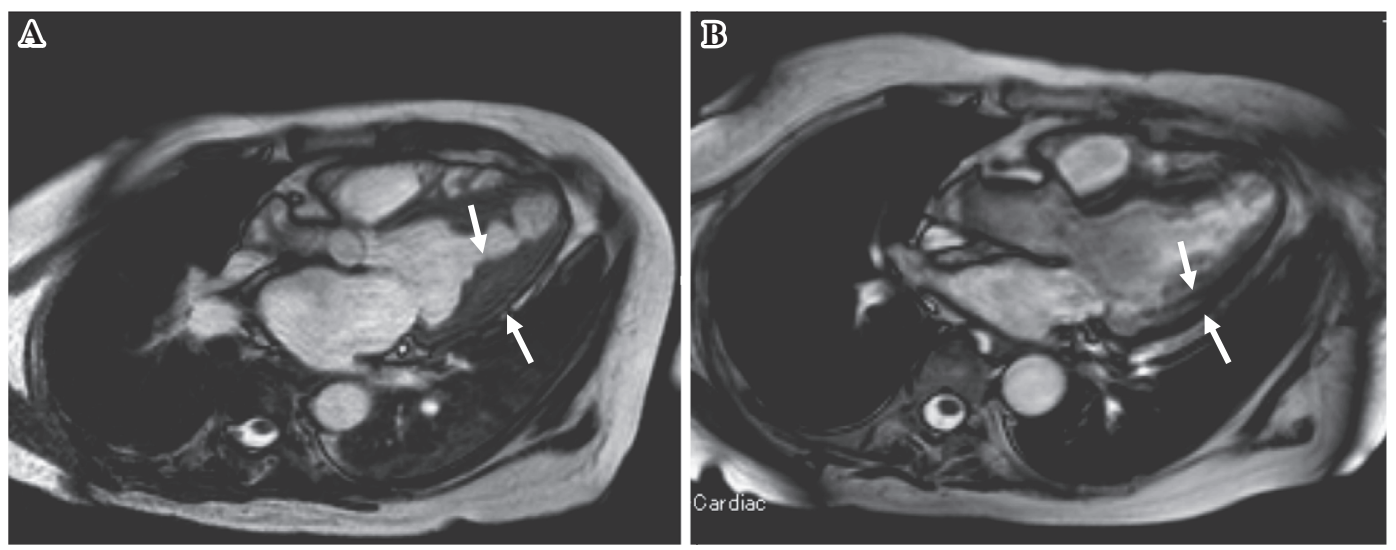

Figure 1. A. End-diastolic image of cardiac magnetic resonance imaging (MRI) before intravenous administration of high-dose human immunoglobulin (IVIg), showing severe wall thickening of the left ventricle (arrow). B. End-diastolic image of cardiac MRI after three courses of IVIg, showing amelioration of the left ventricular wall thickening (arrow) evident in Fig.1 A.

after intubation. Cardiac magnetic resonance imaging (MRI) confirmed sustained LV wall thickening (Fig. 1A). Meanwhile, paresthesia and severe numbness of the extremities markedly progressed. Neurological examination revealed hypotonic tetraparesis [level of manual muscle test (MMT) 12]. CT imaging of the brain showed only old small infarcts that could not explain the paralysis, and a nerve conduction velocity test showed a severely impaired compound muscle action potential (CMAP), suggesting that the symptoms were attributable to mononeuritis multiplex due to CSS. In addition, she had cytomegalovirus (CMV) viremia under such a strong immunosuppressive condition.

Additional mPSL pulse therapy was therefore given simultaneously with IVIg and IVCY, the latter two being repeated 3 times per month. She took a low dosage of IVCY (200 mg/body/day) because of her low creatinine clearance at $56 \mathrm{~mL} / \mathrm{min}$. The levels of CRP and BNP then decreased to $0.01 \mathrm{mg} / \mathrm{dL}$ and $90.6 \mathrm{pg} / \mathrm{mL}$, respectively, and cardiac hemodynamics showed a gradual improvement. Cardiac magnetic resonance imaging also showed improvement of the LV wall thickening (Fig. 1B), and echocardiography showed an increase of stroke volume and improvement of the mid ventricular obstruction. Her neurological symptoms were dramatically improved immediately after the administration of IVIg, and CMAP and MMT were also gradually ameliorated. CMV viremia was improved with ganciclovir administration, and no further adverse event occurred during the treatment (Fig. 2).

Currently the patient is taking $12 \mathrm{mg}$ of oral methylprednisolone daily together with $50 \mathrm{mg}$ of azathioprine, and the disease activity is fully controlled. Her general status has also improved dramatically, and she is able to maneuver a wheelchair unaided.

\section{Discussion}

Cardiac involvement is a major cause of morbidity and mortality in $\operatorname{CSS}(1,9,10)$, and accounts for $33-83 \%$ of deaths due to the disease (11-13). In general, CSS patients respond well to glucocorticoid treatment, and cyclophosphamide can be added if patients are refractory to corticosteroid monotherapy. Several clinical studies have demonstrated an overall remission rate of $81-92 \%$ with such conventional treatments $(14,15)$. However, a small proportion (5-6\%) of patients show no response to combination therapy with corticosteroid and cyclophosphamide. Patients with myocardial involvement in the setting of CSS are sometimes resistant to conventional therapy, and $39 \%$ of such patients die during the acute phase of the disease (14).

Recently, IVIg has been shown to be beneficial for some autoimmune diseases and inflammatory disorders, including idiopathic thrombocytopenic purpura, Kawasaki disease, and Guillain-Barre syndrome. The precise mechanisms underlying the action of IVIg remain unclear, but IVIg is considered to be an immunomodulating agent with multiple activities. These include inhibition of complement binding, prevention of membranolytic attack complex formation, modulation of $\mathrm{T}$ lymphocytes, and neutralization of bacterial and viral superantigens $(16,17)$.

Several case reports and small case studies of CSS have already indicated the possible efficacy of IVIg in patients who are resistant to conventional treatment with corticosteroid and cyclophosphamide (4-7). Tsurikisawa et al demonstrated the efficacy of IVIg therapy for patients with both neurological and cardiac manifestations (6).

The present patient was refractory to two courses of mPSL pulse therapy followed by high-dose PSL, but the association of cytomegalovirus (CMV) viremia raised concerns about increased susceptibility to other infections as a result of the additional immunosuppressive therapy. Therefore we treated the patient with IVIg together with mPSL pulse and low-dose IVCY for disease control, and, in addition, reducing the risk of opportunistic infection. Those therapies were feasible and safe for our patient, and no further adverse event was observed. Although it is difficult to distinguish the individual effects of corticosteroid, IVCY, and IVIg as 


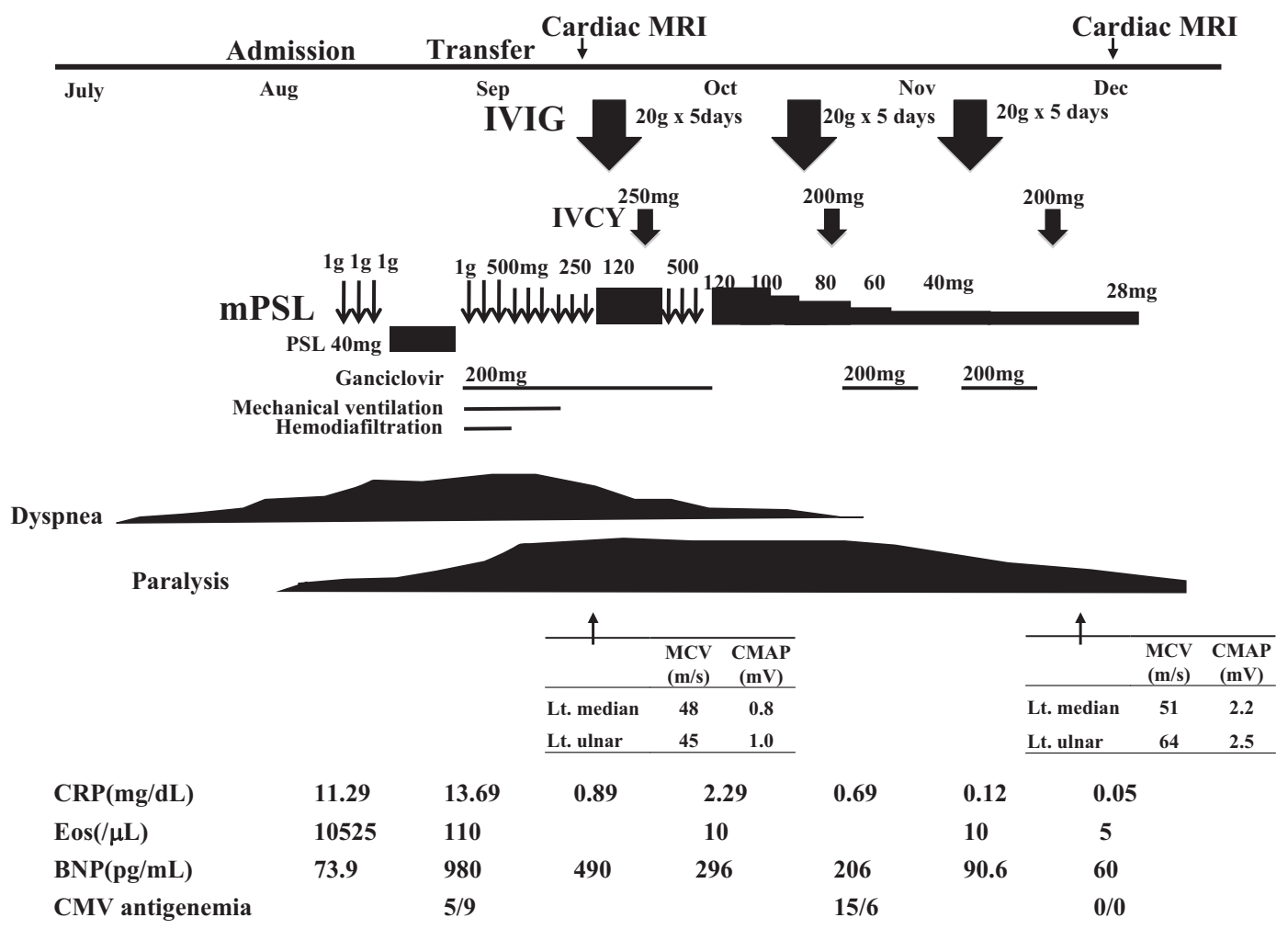

Figure 2. Clinical course.

we used these drugs concomitantly, we believe IVIg was suitable in this case especially for her severe peripheral neuropathy and acute cardiac failure as mentioned previously (6).

The findings in the present case not only support the beneficial effect of IVIg for severe CSS, but also illustrate its safety and tolerability for patients who are immunocompromised. Further studies and accumulation of data will be needed in order to clarify the therapeutic efficacy of IVIg for severe CSS including cardiac involvement or peripheral neuropathy.

\section{The authors state that they have no Conflict of Interest (COI).}

\section{References}

1. Churg J, Strauss L. Allergic granulomatosis, allergic angiitis, and periarteritis nodosa. Am J Pathol 27: 277-301, 1951.

2. Masi AT, Hunder GG, Lie JT, et al. The American College of Rheumatology 1990 criteria for the classification of Churg-Strauss syndrome (allergic granulomatosis and angiitis). Arthritis Rheum 33: 1094-1100, 1990.

3. Noth I, Strek ME, Leff AR. Churg-Strauss syndrome. Lancet 361: 587-594, 2003.

4. Hamilos DL, Christensen J. Treatment of Churg-Strauss syndrome with high-dose intravenous immunoglobulin. J Allergy Clin Immunol 88: 823-824, 1991.

5. Danieli MG, Cappelli M, Malcangi G, Logullo F, Salvi A, Danieli G. Long term effectiveness of intravenous immunoglobulin in Churg-Strauss syndrome. Ann Rheum Dis 63: 1649-1654, 2004.

6. Tsurikisawa N, Taniguchi M, Saito H, et al. Treatment of ChurgStrauss syndrome with high-dose intravenous immunoglobulin.
Ann Allergy Asthma Immunol 92: 80-87, 2004.

7. Takigawa N, Kawata N, Shibayama T, et al. Successful treatment of a patient with severe Churg-Strauss syndrome by a combination of pulse corticosteroids, pulse cyclophosphamide, and high-dose intravenous immunoglobulin. J Asthma 42: 639-641, 2005.

8. Taniguchi M, Tsurikisawa $\mathrm{N}$, Higashi $\mathrm{N}$, et al. Treatment for Churg-Strauss syndrome. Induction of remission and efficacy of intravenous immunoglobulin therapy. Allergol Int 56: 97-103, 2007.

9. Chew CY, Ziady GM, Raphael MJ, Nellen M, Oakley CM. Primary restrictive cardiomyopathy. Non-tropical endomyocardial fibrosis and hypereosinophilic heart disease. Br Heart J 39: 399413, 1977.

10. Guillevin L, Lhote F, Gayraud M, et al. Prognostic factors in polyarteritis nodosa and Churg-Strauss syndrome. A prospective study in 342 patients. Medicine (Baltimore) 75: 17-28, 1996.

11. Chumbley LC, Harrison EG Jr, DeRemee RA. Allergic granulomatosis and angiitis (Churg-Strauss syndrome). Report and analysis of 30 cases. Mayo Clin Proc 52: 477-484, 1977.

12. Lanham JG, Elkon KB, Pusey CD, Hughes GR. Systemic vasculitis with asthma and eosinophilia: a clinical approach to the ChurgStrauss syndrome. Medicine (Baltimore) 63: 65-81, 1984.

13. Bourgarit A, Le Toumelin P, Pagnoux C, et al. Deaths occurring during the first year after treatment onset for polyarteritis nodosa, microscopic polyangiitis, and Churg-Strauss syndrome: a retrospective analysis of causes and factors predictive of mortality based on 595 patients. Medicine (Baltimore) 84: 323-330, 2005.

14. Guillevin L, Cohen P, Gayraud M, Lhote F, Jarrousse B, Casassus P. Churg-Strauss syndrome. Clinical study and long-term followup of 96 patients. Medicine (Baltimore) 78: 26-37, 1999.

15. Solans R, Bosch JA, Perez-Bocanegra C, et al. Churg-Strauss syndrome: outcome and long-term follow-up of 32 patients. Rheumatology (Oxford) 40: 763-771, 2001.

16. Dalakas MC. Mechanisms of action of IVIg and therapeutic considerations in the treatment of acute and chronic demyelinating 
Intern Med 50: 925-929, 2011 DOI: 10.2169/internalmedicine.50.4648

neuropathies. Neurology 59: S13-S21, 2002.

17. Negi VS, Elluru S, Siberil S, et al. Intravenous immunoglobulin: an update on the clinical use and mechanisms of action. J Clin Immunol 27: 233-245, 2007.

(C) 2011 The Japanese Society of Internal Medicine http://www.naika.or.jp/imindex.html 